\title{
A formação do leitor literário na escola e a presença da indústria cultural no processo
}

\begin{abstract}
Resumo
O tema geral do ensaio é o processo de formação do leitor de literatura, especificamente visto a partir de como as relações entre a indústria cultural e a escola afetam, positiva e negativamente, a formação desse leitor. O objetivo é contribuir com o debate sobre formação de leitores a partir de reflexões críticas, elaboradas com o método de levantamento bibliográfico e sistematização de reflexões. Os resultados dessas considerações mostram que uma das principais preocupações dos educadores no processo escolar de formação do leitor diz respeito à seleção de produtos da indústria cultural para uso em sala de aula, já que tal indústria se mostra adultocêntrica e ideologicamente carregada, além de conceber o consumidor (no caso, o aluno) como objeto e não como sujeito.
\end{abstract}

Palavras-chave: Leitores. Formação de Leitores. Leitura Literária. Livros. Indústria Cultural.

\author{
Aline de Mello Sanfelici \\ Universidade Tecnológica Federal \\ do Paraná - UTFPR - \\ Paraná/Brasil \\ alinefelice@gmail.com
}

Fábio Luiz da Silva

Universidade Norte do Paraná UNOPAR - Paraná/Brasil fabio.luiz1@unopar.br

\section{Para citar este artigo:}

SANFELICI, Aline de Mello; SILVA, Fábio Luiz da. A formação do leitor literário na escola e a presença da indústria cultural no processo. Revista Linhas. Florianópolis, v. 18, n. 36, p. 273-284, jan./abr. 2017. 


\title{
The education of the literature reader in school and the presence of the culture industry in the process
}

\begin{abstract}
The broad theme of this essay is the process of literature reader formation. This theme is looked at by focusing on the relationships between the culture industry and the school in terms of how they relate to one another, both positively or negatively, in the reader's formation process. The goal is to contribute to the debate on reader training, through critical reflections achieved by bibliographical research and systematizing of perspectives. The results of the reflections indicate that one of the most relevant concerns of educators in the process should refer to the selection of products from the culture industry to be adopted in the classroom, given that such industry is adult-centered and ideologically charged, and sees the consumer (that is, the student) as an object rather than a subject.
\end{abstract}

Keywords: Readers. Reading Education. Literary Reading. Books. Culture Industry. 


\section{Introdução}

Neste ensaio, abordamos o processo de formação do leitor de literatura. Esse tema é explorado precisamente a partir da seguinte pergunta de pesquisa: como a indústria cultural e o ambiente escolar contemporâneos se inter-relacionam nesse processo de formação do leitor literário? Com tal questão em mente, o objetivo do estudo é refletir sobre a formação do leitor de literatura, especificamente levando em consideração os modos como a indústria cultural atua na escola (e também fora dela), discutindo-se as formas como essas duas entidades (indústria cultural e escola) dialogam entre si e/ou interferem uma na outra.

Antes de iniciarmos nossas reflexões, apresentamos brevemente o entendimento dos elementos norteadores do ensaio. Focalizamos o processo de "formação do leitor" exclusivamente como aquele envolvendo crianças e pré-adolescentes em fase de primeiras aproximações com a literatura, ainda no ciclo fundamental da Educação Básica. Desconsideramos, portanto, processos de formação do leitor adulto ou a questão da leitura em Ensino Médio e preocupada com exames de vestibular. Já em termos da literatura que focamos, dado o exposto anteriormente, será aquela literatura que acompanha o público específico a que nos referimos, ou seja, o infantil e infantojuvenil. Do mesmo modo, a escola que consideramos é, então, centrada na atuação para este público, apenas, e concebida especificamente em um contexto atual de ensino. Tal contexto abarca, portanto, as transformações atuais da sociedade em termos amplos de cultura, tecnologia, ensino, e outras questões relevantes para a área da discussão.

Outro conceito-chave da pesquisa, a indústria cultural, é aqui entendida em um sentido abrangente, como um agente plural, composto pelas mais diversas mídias, como a televisão, a imprensa, a internet, as tecnologias portáteis, além dos elementos de mercado vinculados à produção e consumo de bens, ou seja, editoras, franquias, empresas produtoras de conteúdo midiático, etc. Salientamos que nosso entendimento sobre indústria cultural abrange também sua contemporaneidade, na qual ocorre o "surgimento de novas plataformas midiáticas e de universalização sistêmica dos padrões das mercadorias da indústria cultural, que recombinam gêneros, linguagens e interfaces entre realidade e virtualidade" (COSTA, 2010, p. 89). Desse modo, tal indústria se transforma permanentemente, ao integrar elementos que surgem no cotidiano; ao 
romper antigas dificuldades de acesso e conexão; e ao recriar os produtos culturais sob novas formas e com novos elementos, consumidos de modos igualmente novos.

\section{Métodos}

Para elaborar nossas reflexões, utilizamos o método de pesquisa bibliográfica dentro das áreas pertinentes ao nosso tema maior, ou seja, a formação do leitor literário. Assim, fizemos leitura, fichamento, debate e sistematização de reflexões a partir de estudos críticos sobre indústria cultural, formação de leitores e o lugar da literatura no espaço escolar. O presente ensaio está organizado, então, em quatro breves seções que tratam de pontos que julgamos pertinentes destacar acerca da temática. $\mathrm{O}$ primeiro ponto é o entendimento geral sobre a importância da formação do leitor para o próprio aluno enquanto leitor em formação. O segundo ponto refere-se aos agentes formadores desse leitor, especialmente a escola e a própria indústria cultural, e os ambientes em que tais agentes atuam. A seguir, discutimos alguns problemas das relações entre esses agentes na formação do leitor e, na última seção, dedicamos espaço para apontamento de algumas direções tendo em vista a solução dos problemas discutidos. Por último, apresentamos algumas considerações finais sobre o assunto.

\section{A importância da formação do leitor (e do leitor de literatura, em especial)}

A formação do leitor é essencial para a melhor inserção do sujeito no mundo. Isso pode ser dito considerando-se que, de acordo com Colomer (2007), a tarefa de formar um leitor é parte do processo mais amplo de formação da própria pessoa. Tal perspectiva se apoia na visão de que o leitor, como um indivíduo, precisa construir e desenvolver qualidades como a sociabilidade, e ser preparado para inserir-se no mundo, o qual é marcado por diversidades sociais e culturais e encontros entre tais diferenças. O leitor, também como um sujeito mais amplo, deve ser formado com atenção à sua autonomia e condições apropriadas de analisar e julgar discursos, ideologias, posicionamentos, etc., de modo a ver o mundo da forma mais inteligível possível. Tal inteligibilidade e preparo para a diversidade são cruciais para que o indivíduo se integre e se entenda no mundo, e possa participar dele mais ativamente, de modo crítico, transformador e positivo. 
Partindo da perspectiva acima apresentada, a formação do leitor almeja, então, o que se convenciona chamar de leitor competente. Tal leitor é aquele capaz de construir sentido(s) acerca do que leu, a partir do domínio de certas competências específicas e conhecimentos determinados que lhe possibilitariam ler e interpretar no âmago de um dado contexto cultural. Na visão de Zilberman (2003), é a partir da formação do leitor que se pode mediar o ser humano com o seu tempo presente. Desse modo, a leitura é uma apropriação da realidade, e o leitor competente é capaz de atingir sua emancipação pessoal, sua autonomia, e criar estratégias de articulação e sobrevivência no mundo em que se insere.

A leitura de literatura, em especial, é sentida como organização e representação do imaginário antropológico e cultural da raça humana em que, segundo Colomer (2007), culturas se formam, se encontram e se modificam. Nesse espaço, o leitor de literatura competente e bem formado pode vir a engajar-se em debates diversos e relevantes sobre culturas, ideias e valores, através da sua fruição dos textos literários. Assim, ele não apenas desenvolveria sua capacidade interpretativa e posicionamento crítico como sujeito, como também se prepararia melhor para as realidades variadas que poderia encontrar ao longo de sua vida. Tal leitor inevitavelmente desenvolveria um repertório cultural mais complexo, que possibilitaria sua formação como sujeito de modos mais amplos e amadurecidos.

\section{Quem forma o leitor de literatura}

Conforme explanado por Cosson (2011), na organização escolar em vigência no Brasil, tem-se que o ensino primário sustenta a questão da formação do leitor, desenvolvendo seu gosto pelo imaginário, sua habilidade de interpretação múltipla e significativa, sua sensibilidade, etc. Já o ensino secundário, ou de nível médio, assume o papel de tentar integrar esse leitor recém-formado à cultura da literatura brasileira, ou seja, deve introduzir o leitor ao cânone clássico estipulado em nossa cultura, fazendo-o conhecer seus principais autores, obras e escolas e movimentos literários.

No entanto, observa-se que a formação do leitor ocorre de modos mais amplos do que apenas segundo as diretrizes e os espaços escolares, e tal ponto merece ser olhado 
com mais atenção. Com efeito, a literatura pode, deve, e frequentemente "se encontra" com o sujeito fora dos espaços educacionais tradicionais, de modo que a formação do leitor seja também motivada por essas outras situações. Assim, também são envolvidos no processo de formar o leitor diferentes entidades e profissionais de ordens variadas, e em contextos diversos. Algumas dessas entidades, evidentemente, seriam a própria indústria cultural e suas histórias infantis animadas no Youtube, seu mercado editorial aquecido para o público infantil e infantojuvenil, os shoppings centers ou livrarias ou feiras de livros (ou ainda outros locais como eventos festivos e ONGs) com suas horas do conto e mediações de leitura, entre muitos outros. Professores, autores, editores, mediadores de leitura, bibliotecários, pesquisadores, vendedores, recreadores infantis, entre outros, estão, portanto, entre os profissionais que se integram ao processo amplo da formação do leitor. Assim, o referido processo deve ser entendido como algo não somente interno ao ambiente escolar, mas que também encontra fora da escola uma série de motivadores, agentes e formas de contribuição e/ou interferência.

No que segue, discutiremos a questão da indústria cultural exclusivamente considerada como elemento que adentra as escolas e os processos de formação do leitor literário, tendo, porém, a consciência demonstrada acima de que sua atuação sobre as crianças e jovens se dá, também, para além dos muros da escola.

\section{A formação do leitor e a indústria cultural na escola - Alguns problemas}

Como vimos, a formação do leitor literário se dá com influência dos papéis da escola bem como da indústria cultural, e tais entidades se inter-relacionam a partir do momento que a indústria cultural, como um todo e a partir dos seus produtos, adentra os ambientes escolares, bem como a vida cotidiana dos leitores em formação. Ao mesmo tempo em que é positivo que a formação seja, portanto, um processo de múltiplas vozes e vertentes, há alguns problemas oriundos disso. O leitor em formação evidentemente não permanece indiferente aos efeitos que a indústria cultural e a escola exercem no processo e, como destaca Zilberman (2003), é o adulto quem ocupa lugar central do processo, enquanto agente organizador tanto da indústria cultural quanto da instituição escolar. O leitor em formação, o aluno criança ou pré-adolescente (como definimos para 
os propósitos desse ensaio), acaba por ocupar uma posição periférica, uma vez que, diz Zilberman (2003), é o adulto que determina e cria as histórias, e as edita, distribui, circula, e escolhe qual será consumida, nos diversos papéis de autor, editor, bibliotecário, professor e até mesmo pai ou mãe. O problema que daí decorre é que não são as visões e vozes dos leitores em formação que se destacam, mas sim as dos adultos. Isso poderia dificultar a emancipação do aluno e o desenvolvimento de sua sensibilidade e gosto pessoais, já que os mesmos seriam direcionados conforme as perspectivas dos adultos.

Indo mais adiante nesse ponto, Eagleton (2006) comenta como a centralidade do processo literário nos adultos é marcada por juízos de valor historicamente variáveis e diretamente marcados por ideologias sociais e culturais e, em consequência, questões de poder. A indústria cultural concebe seus consumidores não como sujeitos autônomos, mas como meros objetos prontos a consumir passivamente os seus produtos. Se para um adulto já seria difícil articular-se enquanto ser crítico nesse contexto, sem dúvida para uma criança ou adolescente a dificuldade seria ainda mais evidente. Hunt (2010), de modo similar, diz que os livros para crianças e jovens não são nunca apolíticos ou ideologicamente neutros; ao contrário, justamente por serem produzidos por adultos já intelectualmente desenvolvidos e posicionados ideologicamente, tais livros por vezes mascaram certas ideologias e interesses desses adultos que, como dito, estão no centro do processo cujo receptor final (e intelectualmente menos elucidado) é o aluno leitor em formação. Hunt (2010) também afirma que, mesmo sendo dada a oportunidade de que o aluno escolha o que ler, essa sua suposta escolha já foi moldada e pré-definida pelos adultos e suas ideologias e interesses, visto que foram esses mesmos adultos que elaboraram e disponibilizaram os itens dentre os quais a criança ou pré-adolescente poderia escolher.

Essa relação entre escola e indústria cultural (e a indústria cultural inserida na escola) na formação do leitor literário traz, então, importantes pontos para debate. No âmbito da escola, como a instituição ou o professor poderia decidir a literatura a usar para formar o leitor em sala, e como poderia oferecer liberdade e não limitar o aluno em seus interesses? Como o professor poderia agir para que a formação do leitor de fato respeitasse os interesses desses leitores, crianças e jovens? Tendo em vista as questões ideológicas presentes na produção pela indústria cultural administrada por adultos, o 
professor se vê em dificuldades, nesse sentido. Segundo afirma Cosson (2011), no ato da leitura, abre-se uma porta entre o mundo próprio do leitor e o mundo do outro. Porém, fica a pergunta: quem é esse outro, senão o adulto que produz e seleciona conteúdos e pensamentos, que está atento aos seus interesses e visões de mundo, que é marcado pela indústria cultural que vê seu consumidor (aqui, aluno de ensino fundamental) como objeto? E mais ainda, como o aluno pode despertar seu interesse em formar-se leitor, sem poder escolher o que ler, o que deve ser escrito, o que chegará até sua escola? Vemos que tais pontos são questões que carecem de maior problematização e ação.

Um outro ponto de dificuldade, como observamos com as pesquisas de Zilberman (2003, p. 16), é que até hoje, boa parte da produção literária infantil (assim como da infantojuvenil) se apresenta como uma espécie de "colônia da pedagogia" . Isso significa, para a pesquisadora, que tais obras frequentemente têm apenas um intuito educativo, pragmático ou moralizante, com vias de "dominar" a criança. Tais intuitos acabam prevalecendo sobre as possibilidades estéticas, imaginativas, lúdicas e artísticas para a obra literária e sua leitura, e articulam novamente a questão da visão adultocêntrica da indústria cultural como um agente que pode limitar a liberdade e subjetividade do leitor criança e pré-adolescente. Colomer (2007) argumenta uma visão semelhante, destacando a dificuldade no professorado de levar os alunos à leitura literária justamente em função da chamada "concepção utilitária" da leitura. Nessa concepção, a leitura visa cientificidade através de textos "funcionais", o que pode ser entendido, mais uma vez, como doutrinamento, imposição de ideologias e manipulação do leitor.

Por fim, existem alguns outros problemas na formação do leitor literário e que dizem respeito às relações entre a escola e a indústria cultural, comentados por Colomer (2007). Para a autora, é complicado formar leitores quando a própria organização escolar parece se contradizer, no sentido de diminuir gradativamente o tempo de leitura e reflexão com o avançar das séries. Além disso, a literatura na indústria cultural da atualidade se encontra no interior de um conjunto atraente, variado e amplo de instrumentos de lazer que oferecem técnicas mais complexas de contar a história - por exemplo, com usos de tecnologias. Nesse contexto, o professor de hoje pode inadvertidamente desenvolver um leitor mais afastado do objeto livro e de certas qualidades necessárias à leitura desse livro, como a dedicação de tempo e concentração 
para o encontro e envolvimento adequado e desacelerado com a história. Soma-se a isso a característica de consumo cada vez mais rápido de novidades na indústria cultural, nos dias de hoje, aliado a uma espécie de função profissionalizante da leitura, ou seja, em que ocorre a leitura rápida sem reflexão apropriada. Todos esses fatores são resultado de e se inserem em uma concepção atual do funcionamento da nossa sociedade, em que tudo está conectado e se processa e consome de modo mais rápido, com menos tempo para criticidade, apreciação, entendimento e reflexão.

\section{Articulando a indústria cultural na formação do leitor literário no ambiente escolar - Buscando soluções}

O leitor em formação (criança e jovem) necessita de suporte fora de si que lhe sirva de auxiliar para seu desenvolvimento e experimentação do mundo. Para Zilberman (2003), a literatura oferece justamente tal suporte. Então, a escola e o professor, formando esse leitor de literatura, devem atentar para certas questões à luz das problemáticas adultocêntrica e ideológica da indústria cultural que circundam a literatura na escola. A seguir, veremos algumas possibilidades para buscar soluções ao debate apresentado.

Uma primeira consideração importante é que o fenômeno da leitura não deve ser concebido como simples "absorção" de uma certa mensagem, única e direta, da obra literária. Ao contrário, a leitura deve ser incentivada como um espaço ou atividade que permite o desencadear de múltiplas visões que cada obra sugere, isto é, interpretações variadas e imprevisíveis, e não fechadas ou previamente determinadas pelo professor ou mesmo autor do livro. Desse modo, acreditamos que deva ser dada ênfase às variadas interpretações pessoais dos alunos, pois cada uma dessas interpretações é resultado da percepção singular do universo representado no texto e da compreensão própria e particular do objeto artístico na situação de cada leitor. Assim evita-se (ou pelo menos se reduz) o processo de incutir ideologias e monopolizar as fronteiras do pensamento, e forma-se um leitor mais autônomo e crítico. Colomer (2007), nesse sentido, sugere a prática nas escolas da leitura compartilhada, a qual implicaria compartilhar o entusiasmo com a literatura, a construção do(s) significado(s), as conexões que os livros estabelecem entre os alunos, e as noções de comunidades de leitores em sintonia e diálogo. 
Outra ideia que pode contribuir para solucionar o problema ideológico e adultocêntrico que ocorre na formação do leitor, dados os papéis da indústria cultural e da escola, é considerar que a produção cultural, como um todo, se diversificou. Assim, conforme exposto por Colomer (2007), o arsenal cultural contemporâneo inclui obras com a chamada vocação literária, bem como obras de consumo rápido, livros didáticos, livros de narrações documentais sobre temas da atualidade, livros de autoajuda, entre outros. A seleção do corpus a ser adotado pela escola para formar o leitor literário, evidentemente, é de suma importância, e assim Colomer (2007) orienta que, dada a produção cultural atual diversificada e os interesses diversos dos leitores em formação enquanto sujeitos por eles próprios, vários são os caminhos que podemos seguir. Alguns dos caminhos destacados pela autora incluem: aceitar-se os livros de uma geração; ser atento e respeitoso aos diferentes caminhos e experiências de cada leitor; usar as manifestações dos leitores em formação como insumo para sua própria formação e progressos na mesma; emancipar esses leitores para serem efetivos "donos" de sua leitura e aptos a falar sobre elas; e dedicar tempo e elaborar tarefas que favoreçam o interesse pessoal e estabeleçam essa conexão para os alunos se sentirem pertencentes ao universo dos livros.

Ainda a respeito da seleção de corpus para a formação do leitor literário, Paulino e Cosson (2009) atentam para a importância do professor desse leitor em formação ampliar a relação do aluno com a literatura, o que poderia ser feito com uso de textos da tradição oral, dos meios de comunicação de massa, de outras manifestações artísticas, etc. Cosson (2011) vai além, e postula que o leitor em formação precisa acessar e ter contato com diferentes discursos, conhecer e explorar uma pluralidade e diversidade de autores, obras e gêneros, incluindo o que pertence ao cânone e o que não pertence, o que é conhecido e também o desconhecido, ter contato com o simples e ao mesmo tempo com o complexo, o trivial e o estético, enfim, buscando a gama mais ampla possível de textos diferenciados. Assim, a formação do leitor literário na escola se tornaria uma prática mais democrática e, portanto, menos dependente dos interesses da indústria cultural, que é doutrinadora e pode manipular facilmente a criança ou jovem para certos fins. O processo de formação dos leitores, respeitando o universo de interesse dos alunos, seus itinerários e experiências literárias distintas, e oferecendo 
maior variedade de discursos, passaria então a ser um processo mais aberto para a autonomia, a necessidade e o interesse do próprio leitor em formação.

\section{À guisa de conclusão}

Finalizamos nossas reflexões destacando que a indústria cultural, embora adultocêntrica e propensa a atender ideologias e doutrinas específicas e potencialmente diversas aos muitos interesses e modos de ver e sentir o mundo (de todos os leitores, inclusive as crianças e os pré-adolescentes), é um elemento não apenas presente na sociedade e nos contextos escolares, como também algo que pode ser bem articulado e contribuir positivamente em processos de formação. Para tanto, é preciso que a escola assuma de modo rigorosamente responsável o seu papel formador e, nesse sentido, trabalhe com a questão da formação do leitor de literatura de modo crítico e atento às doutrinas ideológicas que não servem aos educandos, mas sim a uma indústria externa com interesses particulares. Em outras palavras, na prática, é necessário muito rigor e criticidade para selecionar que conteúdos e produtos da indústria cultural deverão adentrar os ambientes escolares (e como os mesmos devem/podem ser tratados), para que os processos de formação de leitores literários não limitem os horizontes de expectativas e experiências dos educandos. Esperamos, então, que as reflexões aqui trazidas, especialmente nesse sentido de seleção de corpus e criticidade dos educadores, possam inspirar a busca por caminhos e soluções aos desafios do processo de formar leitores literários. 


\section{Referências}

COLOMER, Teresa. Andar entre livros: a leitura literária na escola. Tradução de Laura Sandroni. São Paulo: Global, 2007.

COSSON, Rildo. Letramento literário: teoria e prática. 2. ed. São Paulo: Contexto, 2011.

COSTA, Belarmino César Guimarães. Comunicação e educação na era digital: reflexões sobre estética e virtualização. Comunicação, mídia e consumo, São Paulo, v. 7, n. 19, p. 87103, jul. 2010.

EAGLETON, Terry. Teoria da literatura: uma introdução. Tradução de Waltensir Dutra. 4. ed. São Paulo: Martins Editora, 2006.

HUNT, Peter. Crítica, teoria e literatura infantil. Tradução de Cid Knipel. Ed. rev. São Paulo: Cosac Naify, 2010.

PAULINO, Graça; COSSON, Rildo. Letramento literário: para viver a literatura dentro e fora da escola. In: ZILBERMAN, Regina; ROSING, Tânia Mariza Kuchenbecker (Org.). Escola e leitura: velha crise, novas alternativas. São Paulo: Global, 2009. p. 61-79.

ZILBERMAN, Regina. A literatura infantil na escola. São Paulo: Global, 2003.

Recebido em: 30/06/2015 Aprovado em: 30/03/2016

Universidade do Estado de Santa Catarina - UDESC Programa de Pós-Graduação em Educação - PPGE Revista Linhas

Volume 18 - Número 36 - Ano 2017 revistalinhas@gmail.com 